\title{
LA PROTECCIÓN JURÍDICA DE LOS AUTORES DE LAS BASES DE DATOS EN EL DERECHO COMUNITARIO Y EN EL ESPAÑOL
}

\section{Antonlo Pajuelo Macías*}

Resumen: El artículo analiza la protección jurídica de los autores de las bases de datos: la extensión de la protección a las bases de datos electrónicas y no electrónicas; la originalidad del autor en la selección o disposición del contenido de las bases de datos como criterio exclusivo o condición «sine qua non" para su protección; la distinción entre los derechos de autor sobre el contenido de las bases de datos (artículos de revistas, estadísticas... ) y los derechos de autor sobre la selección o disposición de este contenido y, por último, las excepciones o limitaciones a estos derechos.

Palabras clave: autores; bases de datos; derechos de autor; derecho comunitario; derecho español; protección jurídica; bases de datos electrónicas y no electrónicas.

Abstract: This article analyzes the copyright protection of databases; the ex-
tension of this protection to electronic and non electronic databases; the
authors originality in the selection or the arrangement of the contents of the
database as the exclusive criterion or condition «sine qua non» of the copy-
right protection; the distinction between the copyright of the contents of the
databases (literary works, statistics...) and the copyright of the selection or
arrangement of the contents of the databases and, finally, the exceptions to
this copyright.

Key words: authors; databases; copyright; community law; Spanish law; legal protection; electronic and non electronic databases.

\section{Introducción}

Sabido es que las Directivas comunitarias sólo imponen a los estados miembros el cumplimiento del objetivo que en ellas se propone, dejando a la elección de éstos la forma jurídica (ley, decreto, reglamento...) y los medios en que el objetivo se materialice; es decir, dejan a las legislaciones nacionales la elección de aquellas medidas (derechos, obligaciones, sanciones...) que sean necesarias para el cumplimiento del objetivo. Ahora bien, ¿cuál es el objetivo que pretende y exige la Directiva 96/9 C.E., de 11 de marzo, sobre protección jurídica de las bases de datos, que la Ley 5/1998, de 6 de marzo, ha incorporado a nuestro Derecho?

Doble objetivo tiene: proteger los derechos de autor y los de los fabricantes de las bases de datos (Considerando 39, y arts. 3.1 y 7).

De ahí, la estructura de la Directiva: cap. I, «Ambito de aplicación»; cap. II: «Derechos de autor»; cap. III: «Derecho sui generis» (el de los fabricantes) y cap. IV: «Disposiciones comunes».

* Doctor en Derecho y del Cuerpo Facultativo de Archiveros y Bibliotecarios. Madrid.

Recibido: 20-5-99. Segunda versión: 20-10-99. 
En este artículo relacionaremos la Directiva principalmente con la Ley 5/1998. Y al tratar del derecho «sui generis» interpretaremos o desarrollaremos ambas disposiciones con el «Proyecto de Tratado de la OMPI (Organización Mundial de la Propiedad Intelectual) de 1996 relativo a la propiedad intelectual de las bases de datos», pues tal «Proyecto» se refiere a este derecho.

\section{2 Ámbito de aplicación de la Directiva (cap. I)}

\subsection{La forma en las bases de datos: las bases de datos electrónicas y las no electrónicas (art. 1.1)}

La Directiva protege las dos clases de bases de datos, tanto las electrónicas y similares, como las no electrónicas.

$\mathrm{Y}$ así en el Considerando 14 se dice expresa y claramente que «conviene hacer extensiva la protección prestada por la presente Directiva a las bases de datos no electrónicas»; y el art.1.1 afirma que «la presente Directiva se refiere a la protección jurídica de las bases de datos sean cualesquiera sus formas». Lo vuelve a repetir en el n.2 de este artículo, al definir las bases de datos.

En el mismo sentido, el art..$^{\circ}$ de la Ley $5 / 1998$ (y también al definirlas) considera que las bases de datos pueden ser «accesibles... por medios electrónicos o de otra forma».

Hay que notar que, anteriormente, sólo se proponía protección jurídica a las bases de datos electrónicas y similares. Así, en la Propuesta de Directiva 92/C 196, de 15 de abril: «la presente Directiva está destinada a proteger las colecciones... cuya disposición, almacenamiento y acceso se efectúan mediante procedimientos electrónicos, electromagnéticos, electrópticos u otros similares» (Considerando 13) y el Considerando 19 sobreentiende que la protección sólo se aplicará «a las colecciones realizadas mediante medios electrónicos».

Por ello, el art. 1.1 de esta Propuesta consideraba bases de datos sólo las «accesibles mediante medios electrónicos»; lo cual entendía «sin perjuicio de la protección mediante el derecho de autor de las colecciones... accesibles por medios no electrónicos» prevista en el art. 25 del Convenio de Berna de 2 de julio de 1973.

Por lo tanto, la protección jurídica de las bases de datos no electrónicas se remitía a este Convenio, en vez de regularla directamente en la Propuesta de Directiva.

Sin embargo, como veremos luego, el articulado de la Directiva, en lo referente a los derechos de explotación de las bases de datos, distinguirá las bases de datos electrónicas de las no electrónicas, protegiendo más aquéllas. En el mismo sentido la Ley 5/1998.

\subsection{Definición de las bases de datos (art. 1.2)}

En cualquiera de las citadas disposiciones, las bases de datos son colecciones, recopilaciones o compilaciones de obras (textos completos o en resumen, sonidos, imágenes...), de datos (hechos, estadísticas...) o de otros elementos independientes dispuestos o seleccionados de manera sistemática o metódica y accesibles por medios electrónicos o de otra forma. 
Si las disposiciones protegen las bases de datos, según esta definición de las mismas se protegerán entonces: a) no sólo las textuales; b) pero no la fijación (como tal) de una obra audiovisual, cinematográfica, literaria o musical (Considerando 17).

La definición no abarca las bases de datos originales y las no originales, porque por derecho de autor no se pueden proteger las no originales (al no ser objeto de propiedad intelectual).

Pero sí por el derecho «sui generis»; cuyo objeto es la simple inversión. Es decir, basta ésta para la protección. A diferencia del objeto de los derechos de autor que es la selección o disposición de las recopilaciones, cuando constituyan creaciones intelectuales.

Precisamente la legislación de los países escandinavos elaboró un derecho especial para aquellas antologias (antecedentes de las bases de datos) que no reuniesen las condiciones para estar protegidas por derecho de autor.

Pero ni siquiera en el «Proyecto de Tratado» citado (que regula el derecho «sui generis») se da una definición de las bases datos que abarque tanto las originales como las no originales.

\subsection{Limitación del ámbito de aplicación de la Directiva (art. 1.3)}

La protección de esta Directiva no se aplicará a los programas de ordenador utilizados en el funcionamiento o la fabricación de bases de datos accesibles por medios electrónicos.

Tampoco al alquiler y préstamo de las bases de datos. La razón de estas exclusiones es que estas materias tienen ya sus propias Directivas o su propia legislación nacional.

En cambio, la Directiva de la que estamos tratando, la 96/9, podrá aplicarse igualmente a los elementos necesarios para el funcionamiento o la consulta de determinadas bases de datos, como el tesauro o los sistemas de indización (Considerando 20). Lo cual sucederá en las bases de datos de los fondos de una biblioteca.

Es lógica la inclusión en la protección, pues se trata de elementos necesarios. Y ello, aunque no figure en el articulado. Lo mismo cabría decir de la inclusión de dispositivos tales como los CD-ROM y los CD-I en bases de datos electrónicas (Considerando 22).

\section{Derechos de autor (cap. II)}

3.1 La originalidad en la selección o en la disposición del contenido de una base de datos, criterio único para protegerlas jurídicamente (art. 3.1)

Así se expresa el Considerando 16 y el art. 3.1 acerca de la originalidad, en el sentido de creación intelectual.

La originalidad es, como se dice en la Exposición de Motivos de la Ley 5/1998, requisito «sine qua non» para aplicar la protección a una base de datos mediante derechos de autor. De modo que una base de datos no original no estará protegida mediante derechos de autor. 
Es el mismo requisito exigido para la protección de obras literarias, artísticas o científicas en general: «La protección intelectual de una obra literaria, artística o científica, corresponde al autor por el solo hecho de su creación» (art. 1, Texto Refundido de la Ley de Propiedad Intelectual aprobado por R. D. Legislativo 1/1996, de 12 de abril).

Por ello, «son objeto de propiedad intelectual todas las creaciones originales, literarias, artísticas o científicas» (ibidem, art. 10) y, por lo mismo, «también son objeto de propiedad intelectual las bases de datos que por la selección o disposición de sus contenidos constituyan creaciones intelectuales» (art.1. ${ }^{\circ}$ de la Ley $5 / 1998$ que da así nueva redacción al art. 12 del T.R., al incluir expresamente el término «base de datos»).

Idéntica modificación realizó la Loi 97-283, du 27 de mars, en el art. 112-3 del Code de la Propiété Intellectuale (Loi 92-597, du ler. juillet).

Por su parte, el artículo 2.5 del Convenio de Berna exige también la creación intelectual como requisito para la protección de las compilaciones, las antecesoras de las bases de datos: «Las colecciones de obras literarias o artísticas..., que por la selección o disposición de los materiales consituyan creaciones intelectuales, serán protegidas como tales».

De ahí que la Ley 5/1998 incorpore la Directiva comunitaria directamente en el T.R. de la Ley de Propiedad Intelectual, modificando, o dando nueva redacción, a los artículos de ésta para cumplir el objetivo propuesto en la Directiva. Es decir, la Ley 5/1998 queda subsumida en el T.R.

La protección de las bases de datos mediante derechos de autor explica esta directa incorporación de la Ley 5/1998 en el T.R. Razones de eficacia y de economía legislativa pueden justificar también dicha incorporación.

Es la misma solución de la correspondiente Ley, de 22 de julio de 1997, de trasposición al Derecho alemán de la Directiva que estamos tratando. El legislador alemán decidió integrar dicha Ley en la Ley de Derechos de Autor de 9 de set. de 1995.

Y como vimos, también la Ley francesa 97-283 hace lo mismo.

\subsection{El término «originalidad»}

Hemos estado tratando de la originalidad, en el sentido de creación intelectual.

Pero, ¿qué se entiende por «originalidad»?

En el art. 2.5 del Convenio de Berna la originalidad hace referencia al concepto de creación intelectual.

Sin embargo, su sentido varía según los distintos ordenamientos jurídicos.

Por razones históricas, entre otras, en los países de la «Common Law» (Reino Unido, Canadá...) lo original casi equivale a lo que no se ha copiado. Así lo entiende la jurisprudencia canadiense. En sentido opuesto, y por las mismas razonas, en los países donde impera el derecho civil, en los países latinos, la originalidad significa la creatividad personal, y, en cierto sentido, única.

La Directiva 96/9 aunque no utilice para la originalidad el término «no copia», sin embargo, en el fondo es ésta la posición que parece adoptar en el art. 3.1: «las bases de datos que por la selección o la disposición de su contenido constituyan una creación intelectual de su autor estarán protegidas, como tal creación, por los derechos de autor». En el mismo sentido, el Considerando 15 no admite otro criterio de protección, sino «la creación intelectual propia del autor». 
El adjetivo «propia» añadido a los términos «creación intelectual» da la pauta para esta interpretación. Es decir, según el art. 3.1 y el Considerando 15, es la creación intelectual propia, la del autor, no la copiada o repetida, la que se protege mediante derechos de autor por la Directiva.

La Ley alemana de trasposición, antes citada, no recoge explícitamente este adjetivo, pero lo cambia por el de personal. Por lo tanto, para la Ley alemana el criterio de protección es la «creación intelectual personal» que viene a ser lo mismo que el de "creación intelectual propia" (art. 7 que modifica el art. 4 de la Ley de Derechos de Autor, de 9 de set. de 1995).

Por lo demás, esta interpretación no es nueva en la legislación comunitaria.

Efectivamente, la Directiva 91/250 sobre la protección jurídica de los programas de ordenador utiliza el mismo criterio de originalidad en el sentido de creación intelectual propia: «el programa de ordenador quedará protegido si fuese original en el sentido de ser una creación intelectual propia de su autor...» (art. 1.3). En el mismo sentido, el art. 1.3 de la Ley 16/1993, de 23 de dic., que incorpora al Derecho español esta Directiva: «El programa de ordenador será protegido únicamente si fuese original en el sentido de una creación intelectual propia de su autor». Asimismo la Directiva 93/98, en su art. 6, sobre la duración de la proteción en las fotografías.

Ahora bien, tal adjetivo curiosamente no está en la Ley 5/1998: «también son objeto de propiedad intelectual... las bases de datos que por la selección o disposición de sus contenidos constituyan creaciones intelectuales» (art. $1^{\circ}{ }^{\circ}$ ); tampoco aparecía tal adjetivo en el antiguo art. 12 del T.R., al tratar de las colecciones como objeto de propiedad intelectual.

Pero el que la Ley 5/1998, o el Convenio de Berna, entiendan originalidad en el sentido de creación intelectual, como lo hace el Considerando 16 de la Directiva, no parece tener otro sentido que exigir algo más que la simple «no copia»; de modo que la originalidad no quede reducida a esto, sobrentendiéndose además que la base de datos ha de ser una creación intelectual propia, es decir, no ajena o repetida, si verdaderamente es original.

Por otra parte, el art. 3.1 de la Directiva que parece reducir la originalidad a la simple «no copia» va acompañado de ciertas ambigüedades.

Por ejemplo, el art. 1.2 (al definir las bases de datos) indica que el contenido de éstas («obras, datos u otros elementos») ha de estar «dispuesto de manera sistemática o metódica». Lo cual significa que tal disposición ha de ser una creación intelectual, y, consiguientemente, original. Es decir, se exige de la originalidad algo más que una simple «no copia».

Además, el Considerando 21, para explicar el sentido de tal disposición, la opone «al almacenamiento físico de forma organizada». Pero tal almacenamiento es difícil imaginarlo en las bases de datos electrónicas, por lo que resulta inútil oponerlo a la disposición «metódica o sistemática», y además, ¿qué distinción hay entre tal disposición y tal almacenamiento en forma organizada?

Por otra parte, si la originalidad en el sentido de creación intelectual se centra en la selección o disposición de las materias contenidas en las bases de datos (art. 3.1 y Considerando 15 ; y art. $1 .^{\circ}$, Ley $5 / 1998$ ), es frecuente que la «selección» no presente ninguna originalidad, cuando el autor de la base de datos se proponga incluir en ella todos los datos que se sitúan en el ámbito de la base, en cuyo caso lo que falta es la «selección» propiamente dicha. Lo cual sucederá en las bases de datos que pretendan ser exhaustivas. 
Tampoco habrá originalidad en la disposición del contenido, si la base de datos es electrónica, y únicamente basta «memorizar» la materia desordenada. Con un buen programa de ordenador se podrá recuperar el punto que se desee, aunque el contenido esté todo desorganizado.

A este respecto, la jurisprudencia alemana ha negado originalidad y, consiguientemente, protección a una bibliografía, a una compilación de leyes editada en CD-ROM o a la utilización de guías telefónicas en CD-ROM.

\subsection{Los derechos de autor sobre el contenido de las bases de datos (art. 3.2)}

La protección jurídica de las bases de datos «no podrá hacerse extensiva a su contenido y se entenderá sin perjuicio de los derechos que pudieran subsistir sobre dicho contenido». En el misno sentido el art. $1 .^{\circ}$ de la Ley 5/1998.

Se reconocen, pues, en ambos textos, dos clases de derechos de autor (además del otro derecho «sui generis») con objeto diferente: por una parte, los derechos exclusivos sobre el contenido de las bases de datos (los datos u otros elementos incorporados a ella) (Considerando 26, art. 3.2; y art. 1. ${ }^{\circ}$, Ley 5/1998) y, por otra parte, e independientemente, los derechos, también exclusivos, de los autores de las bases de datos, derechos referidos solamente a la "estructura» de las mismas, «en cuanto forma de expresión de la selección o disposición de sus contenidos» (Considerandos 27 y 35). Por ello, «los datos protegidos por derecho de autor... incorporados a una base de datos siguen siendo objeto de los derechos exclusivos... (del autor de ellos), por lo que no pueden incorporarse a una base de datos o extraerse de ella sin el permiso del titular de los derechos o de sus derechohabientes".

Concretando estos derechos exclusivos sobre el contenido de las bases de datos, el Informe de la Comisión de las CCEE COM (90) 584 final (Bruselas, 17 de enero de 1991, "Acciones derivadas del Libro Verde») recoge entre las coclusiones unánimes que «la inclusión bibliográfica de obras protegidas sin la autorización de su titular no constituye una infracción de los derechos de autor. Lo mismo puede decirse de los resúmenes de obras protegidas, siempre que no sirvan para sustituirlas...».

Pero según la legislación española, los resúmenes de obras protegidas son objeto de propiedad intelectual (art. 11.3..$^{\circ}$. Lo cual no habrá que entenderlo de los breves y elementales resúmenes de una obra, sino de los llamados «abstracts» o resúmenes más completos y elaborados que dan cuenta de tesis o características más importantes de las obras.

Por supuesto, parece claro que la inclusión de textos completos de obras protegidas también es objeto de propiedad intelectual y, por lo tanto, necesita la autorización, como los «abstracts» dichos, del autor de los mismos para su inclusión en una base de datos.

En relación con las referencias bibliográficas de obras protegidas (título, autor, editorial...) no hay nada expreso en nuestra legislación respecto a su protección. Tampoco la legislación alemana las reconoce como creación intelectual personal, no susceptibles, consiguientemente, de protección. Dado que no parece que haya explotación de la obra, habrá que concluir su no protección. 


\subsection{Los derechos de autor sobre la estructura de las bases de datos: Actos sujetos a restricciones (art. 5 de la Directiva)}

Al estar las estructuras protegidas por los derechos de autor, habrá que reconocer a sus autores o creadores el derecho moral y los derechos patrimoniales o de explotación propios de la propiedad intelectual.

\subsubsection{El derecho moral de los autores de las bases de datos «no entra en el ámbito de aplicación de la presente Directiva»}

Ya que ésta remite su ejercicio a las legislaciones de los estados miembros y al Convenio de Berna (Considerando 28; art. 6 bis.1. ${ }^{\circ}$ del Convenio).

Lo cual quiere decir que no se puede acudir a la Directiva para proteger el derecho moral sobre una base de datos.

Y sobre este derecho moral la Ley 5/1998 no introduce ninguna modificación en el T.R.

Por ello, hay que acudir a este texto, en concreto y en definitiva a sus arts. 14 a 16 que están dentro del Libro I.

\subsubsection{Derechos patrimoniales o de explotación de los autores de una base de datos}

La Directiva los reconoce, expresa y ampliamente, aunque de una manera vaga, es decir, sin concretar todos ellos. Reconoce, por tanto, el derecho de autorizar o realizar la reproducción, distribución, comunicación pública y transformación referido, claro está, a la forma de expresión de las bases de datos, esto es, referido a su estructura, no a su contenido.

Estos derechos implican, pues, que actos de no titulares están sujetos a restricciones, aunque la legislación también reconoce excepciones a los actos sujetos a restricción.

Tanto en los derechos de reproducción y distribución, como en el derecho moral (como vimos) la Ley 5/1998 no ha introducido ninguna modificación; no necesaria, por otra parte, según la opinión de F. Bondía Román.

\subsubsection{La reproducción}

Respecto a ella no puede ser más amplia la Directiva, como decíamos, ya que en su art. 5 a) dice así: «el autor de una base de datos tendrá el derecho exclusivo... de realizar o autorizar: la reproducción temporal o permanente, total o parcial, por cualquier medio y de cualquier forma».

Términos amplios "por cualquier medio y de cualquier forma», pero vagos, pues no se concretan ni los medios ni las formas.

También hay amplitud en los términos «reproducción temporal o permanente».

Consiguientemente, aunque en el articulado no esté explícita y concretamente la reproducción electrónica o informática (es decir, la conseguida por la carga o almacena- 
miento de material digitalizado en la memoria de un ordenador u otro sistema o aparato electrónico), hay que considerarla protegida dada la amplitud con que está redactado el artículo 5 a) de la Directiva.

Lo mismo cabe decir de la trasmisión material de una manera efímera a través de redes como Internet.

Por lo demás, esta amplitud se encuentra también en la Directiva 91/250 CEE, de 14 de marzo, sobre protección jurídica de los programas de ordenador: «Actos sujetos a restricciones... la reproducción total o parcial de un programa de ordenador por cualquier medio y bajo cualquier forma, ya fuera permanente o transitoria» (art. 4. ${ }^{\circ}$ a). Este artículo está reproducido literalmente en el $4 .^{\circ}$ a) de la Ley 16/1993, de 23 de dic., Ley de transposición al Derecho español.

La misma amplitud en el art. $9 .^{\circ} .1$ del Convenio de Berna referente a la protección de obras literarias y artísticas.

Sin embargo, la Ley $5 / 1998$ no da nueva redacción al art. 18 que se limita a definir qué se entiende por reproducción. Tal vez se ha considerado que no se necesita nueva redacción, pues la amplitud parece deducirse de la misma definición al incluir en ella como reproducción «la fijación de la obra en un medio que permita su comunicación».

De todas maneras, no se concreta esta «fijación», ni siquiera se alude en ella a «la reproducción temporal o permanente, total o parcial».

Por lo tanto, la Ley española resulta más vaga, menos concreta, al no ser redactado de nuevo el art. 18 del T.R.

Pero acerca de la reproducción para fines privados, y en el proceso de consulta que recoge el «Seguimiento del libro Verde sobre Derechos de autor... en la Sociedad de la Información», «la mayoría de los titulares, editores e interesados del sector se oponen a cualquier tipo de excepción en relación con la copia privada... en el entorno digital, aduciendo que estas reproducciones perjudicarán la explotación normal de las obras... ya que se espera que la nueva tecnología permita en breve el control eficaz de la reproducción privada».

La Directiva se hizo eco de este "proceso de consulta», y en el art. 6.2 a) dispone que «los estados miembros podrán imponer limitaciones... cuando se trate de una reproducción con fines privados de una base de datos no electrónica».

Aquí sí que la Ley 5/1998, en consonancia con la Directiva, dice expresamente que «no se necesitará la autorización del autor de una base de datos protegida... cuando tratándose de una base de datos no electrónica se realice una reproducción con fines privados» (art. 34.2 a).

Por lo tanto, la reproducción de una base de datos electrónica necesitará la autorización del autor de la misma aunque sea para usos privados; es decir, tal reproducción no será un caso de excepción de los actos sujetos a restricciones (contemplados en el art. 6 de la Directiva en relación con el art. 5 de la misma); ya que sólo de las bases de datos no electrónicas se afirma expresamente que podrán reproducirse para fines privados sin autorización del titular de las mismas.

Consecuencia final: las bases de datos electrónicas se protegen más que las no electrónicas, ya que, cuando se trate de las bases no electrónicas, los estados miembros podrán imponer limitaciones a su reproducción con fines privados. La Directiva sólo habla de esta posiblidad jurídica.

Por su parte, la Ley alemana de trasposición dicha dispone que no hace falta auto- 
rización para la reproducción con fines privados incluso de bases electrónicas. Entendiendo de otra manera la posibilidad dicha de los estados miembros. Pero esta Ley alemana de trasposición de la Directiva ha sido objeto de reparos por la Unión Europea.

\subsubsection{La comunicación al público}

Al aplicarse la Directiva a cualquier forma de base de datos, es decir, al entrar dentro del ámbito de su protección tanto las bases de datos electrónicas como las no electrónicas (art. 1 y 2, Considerando 14) y al entender como actos sujetos a restricciones «cualquier forma de comunicación, exhibición o representación», la Ley $5 / 1998$ ha tenido que redactar de nuevo la letra «i» del art. 20.2 del T.R. (art. $22^{\circ} .1$ de la Ley de trasposición).

Especialmente son actos de comunicación pública «...el acceso público en cualquier forma a las obras incorporadas a una base de datos...».

Esta letra «i» del T.R. estaba redactada así: «Especialmente son actos de comunicación pública... el acceso público a bases de datos de ordenador por medio de telecomunicación...».

Esto es, según la redacción antigua, sólo el acceso público a bases de datos electrónicas se consideraba acto de comunicación pública y, por lo tanto, objeto de derecho exclusivo de explotación por su titular; de modo que el acceso público a una base de datos no electrónica sería libre, no necesitaría la autorización del titular de la base de datos.

Consiguientemente, según la nueva redacción, si es «comunicación pública el acceso público en cualquier forma a las obras incorporadas a una base de datos, sólo el autor de las mismas tendrá derecho exclusivo de realizar o autorizar la comunicación pública" tanto de las bases de datos electrónicas como de las no electrónicas (art. 5. d).

En concreto, tendrá derecho exclusivo de autorizar o realizar las llamadas «transmisiones electrónicas a la carta», esto es, la trasmisión electrónica de bases de datos por redes como Internet al ordenador personal $u$ otra unidad digital de usuario en un momento escogido por éste («a la carta», pues). (Del «Seguimiento al Libro Verde sobre los Derechos de autor... en la Sociedad de la Información».)

Y ello sin perjuicio de los actos de reproducción que lleve consigo la «transmisión electrónica», que se cubrirán por el de derecho específico de reproducción.

La Directiva, como vimos en la reproducción, ha optado por un concepto amplio de comunicación pública, en vez de concretar los actos en que se materialice. De esta manera se quieren abarcar todos los supuestos que en el futuro se puedan presentar.

Explícitamente las «trasmisiones a la carta» no están en la Directiva, pero se incluyen en el art. $5 \mathrm{~d}$ ), dado su concepto amplio de «comunicación pública».

Además, la Ley 5/1998, de acuerdo con la amplitud dicha del art. 5 d) de la Directiva, añade la letra «j» al art. 20.2 del T.R.: «Especialmente son actos de comunicación pública... la realización de cualquiera de los actos anteriores respecto de una base de datos protegida por el Libro I de la presente Ley» (esto es, protegida por los derechos de autor) (art. $2^{\circ} .2$ ).

Si entre tales actos anteriores está el «acesso público» de la letra «i», aunque la base de datos «no esté protegida por los derechos de autor», dicho acceso se considera «comunicación pública».

Es decir, el acceso público a las obras incorporadas a una base de datos sólo se protegía «cuando éstas incorporen o constituyan obras protegidas» (antigua redacción de 
la letra «i» del art. 20.2 del T.R.). Ahora dicho acceso se protege, aunque las bases de datos no estén protegidas por derechos de autor (nueva redacción de esta letra).

\subsubsection{La distribución al público}

El art.19.1 del T.R. define la distribución como «la puesta a disposición del público del original o copias de la obra mediante su venta, alquiler, préstamo o de cualquier otra forma».

En un sentido más amplio, sin concretar, el art. 5 c) de la Directiva dispone que «el autor de una base de datos tendrá el derecho exclusivo de realizar o autorizar... cualquier forma de distribución al público de la base de datos o de copias de la misma».

Pero el Considerando 24 advierte que «el alquiler y el préstamo de las bases de datos en el ámbito de los derechos de autor... se rigen exclusivamente por la Directiva 92/100 CEE, de 19 de noviembre».

Por ello, la Directiva 96/9, de la que estamos tratando, dispone que ella «se aplicará sin perjuicio de las disposiciones comunitarias relativas al... derecho de arrendamiento y de préstamo... en el ámbito de la propiedad intelectual».

De ahí que al tratar del derecho de distribución al público de una base de datos o de copias de la misma, sólo habla de la venta de ellas; disponiendo que «la primera venta en la Comunidad de una copia de la base de datos por el titular del derecho o con su consentimiento extinguirá el derecho de control de las ventas sucesivas de dichas copias en la Comunidad» (art. $5 \mathrm{c}$ ).

Esto quiere decir que el derecho exclusivo de distribución de su titular queda agotado cuando se comercializan copias con su consentimiento; porque si se comercializan copias sin su consentimiento, o él no las realiza, las ventas efectuadas son «piratería» sujeta a la legislación penal de los estados miembros.

Es esta comercialización sin el consentimiento dicho la que distingue la «piratería» de las reproducciones con fines privados en las que falte la autorización.

Ahora bien, el art. 5 c) sólo contempla el agotamiento del derecho de venta en la Comunidad; pero no el agotamiento internacional de este derecho que significa que se agotará por la venta autorizada en cualquier parte del mundo.

Consiguientemente, «cuando un titular de un país aplica el principio comunitario tendrá derecho a bloquear las importaciones de otro estado miembro que aplicara el principio de agotamiento internacional, si en dicho estado el producto en cuestión lo comercializó en la Comunidad un tercer interesado sin el consentimiento del titular» («Seguimiento del Libro Verde sobre Derechos de Autor... en la Sociedad de la Información).

En consonancia con el principio de agotamiento del derecho de venta en el ámbito de la U.E. está redactado el art. 19.2 del T.R.; por ello, la Ley $5 / 1998$ no ha modificado su redacción.

Hay una excepción en dicho principio, según el Considerando 33 de la Directiva, pues afirma que no se da en el caso de explotación de bases de datos en línea, al considerarla explotación de servicios.

Pero los articulados respectivos, el de la Directiva y el de la Ley $5 / 1998$, no han recogido dicha excepción. ¿Quiere esto decir que las legislaciones nacionales no estarán obligadas a recogerla? 
Dejemos este problema de la posible obligatoriedad de los Considerandos para las legislaciones nacionales.

\subsubsection{La transformación}

La inclusión por la Directiva, en su art. 5 b), de la reordenación de una base de datos en la transformación de la misma ha obligado a la Ley $5 / 1998$, en su art. 3..$^{\circ}$, a dar una nueva redacción al art. 21.1 del T. R.: «Cuando se trate de una base de datos... se considerará también transformación la reordenación de la misma». Se entenderá siempre que ésta suponga una cierta y relativa originalidad.

\subsection{Excepciones o limitaciones à los actos sujetos a restricciones}

\subsubsection{Reproducción sin autorización}

Teniendo en cuenta que, según el art. 6 de la Directiva, en algunos casos los «Estados miembros podrán imponer limitaciones a los derechos contemplados en el art. 5 (los derechos exclusivos del titular de realizar o autorizar la reproducción...), el art. 3 de la Ley 5/1998 (que trata de la «reproducción sin autorización») permite que las «obras ya divulgadas podrán reproducirse sin autorización del autor..., para: $11^{\circ} \ldots$ constancia en un procedimiento judicial o administrativo; $2 .^{\circ}$ uso privado del copista ... y 3. ${ }^{\circ}$ uso privado de invidentes...».

La nueva redacción del art. 31 del T.R. añade que ello ha de ser «sin perjuicio, en lo pertinente, de lo dispuesto en el art. 34 de la Ley 5/1998.

Ahora bien, lo «pertinente» del art. 34 es que sólo la reproducción para uso privado de una base de datos no electrónica no necesita autorización del autor, "siempre que la copia no sea objeto de utilización colectiva ni lucrativa" (arts. 34.2 a) y 31 de la Ley; art. 6.2 a) de la Directiva).

En cambio, «a sensu contrario», sí la necesitará la reproducción de una base de datos electrónica, aunque sea para uso privado.

Esta limitada autorización de reproducción para uso privado se entiende concedida a cualquier persona; es decir, no sólo al «usuario legítimo». Lo mismo cabe decir de las otras dos autorizaciones de «utilización» de una base de datos contenidas también en el art. 34.2 : «la utilización con fines de ilustración de la enseñanza o de investigación científica»... y «la utilización para fines de seguridad pública o a efectos de un procedimiento administrativo o judicial».

\subsection{2 «Usuario legítimo»}

Lo es la persona que tiene derecho a utilizar la base de datos, porque ha obtenido de su titular la autorización para utilizarla, como consecuencia de compraventa, alquiler o préstamo del original o copia de la base de datos.

Y dentro de las «Disposiciones comunes», el art. 15 de la Directiva impone «carácter imperativo a determinadas disposiciones» de modo que «serán nulos de pleno 
derecho cualesquiera pactos contrarios a lo dispuesto en el apartado 1 del art. 6 («excepciones a los actos sujetos a restricción del usuario legítimo») y en el art. 8 («derechos y obligaciones del usuario legítimo»).

Ahora bien, en un pacto entre el titular del derecho de una base de datos y un usuario al que autorice el uso de la misma, el usuario (que es legítimo entonces) "podrá efectuar sin autorización de aquél todos los actos a los que se refiere el art. 5 (reproducción, modificación...) que sean necesarios para el acceso al contenido de las bases de datos y a su normal utilización por el propio usuario" (art. 6.1).

Es decir, el titular no puede imponer al usuario legítimo la necesidad de su autorización para lo que sea imprescindible al acceso al contenido de la base de datos; en concreto, no podrá imponer autorización para la reproducción, modificación... que sean necesarias para tal acceso. Tales pactos serán limitados, pues, dado el «carácter imperativo" del art. 15.

Y «en la medida en que el usuario esté autorizado a utilizar sólo una parte de la base de datos, el presente apartado será aplicable únicamente a dicha parte».

El art. 34.1 de la Ley 5/1998 reproduce literalmente el art. 6.1 de la Directiva.

Por otra parte, la letra d) del art. 6 permite a los estados miembros imponer otras excepciones a los derechos de autor sin perjuicio de lo dispuesto en las letras a) utilización con fines privados de bases de datos no electrónicas; b) utilización con fines exclusivos de investigación científica o de ilustración de enseñanza..., y c) utilización con fines de seguridad pública o a efectos de un procedimiento administrativo o judicial.

Pues bien, ya el art. 37.1 del T.R. disponía que los «titulares de los derechos de autor no podrán oponerse a las reproducciones de obras cuando aquéllas se realicen sin finalidad lucrativa por los museos, bibliotecas, fonotecas, filmotecas, hemerotecas o archivos de titularidad estatal ... y la reproducción se realice exclusivamente para fines de investigación científica».

Por lo tanto, los fines exclusivos de investigación científica están permitidos en general sin autorización del titular (por el art. 34.2 b) y en concreto, tratándose de las instituciones dichas (art. 37.1), «indicando en cualquier caso su fuente» (art. 34.2 b). Este art. 37.1 no ha sido modificado por la Ley 5/1998.

\section{Conclusiones}

4.1 Las bases de datos no son sólo compilaciones textuales; porque son compilaciones, colecciones o recopilaciones de datos, hechos o cifras (estadísticas...) y de obras (textos completos o, en resumen, literarios o artísticos; sonidos; imágenes...) o de otros elementos independientes dispuestos o seleccionados de una forma metódica o sistemática y accesibles individualmente.

Y si la Directiva 96/9 y la Ley 5/1998 protegen a los autores de las bases de datos, no protegerán a los autores de simples fijaciones de una obra audiovisual, cinematográfica, literaria o musical; porque no son bases de datos.

Al contrario, se protegerán también aquellos elementos que en algunas bases de datos son necesarios para su consulta o funcionamiento, como el tesauro y los sistemas de indización. Tal sucederá, por ejemplo, en las bases de datos de artículos de revistas o de libros de una biblioteca.

4.2 Puesto que en las bases de datos, una vez producidas, hay tres elementos: da- 
tos y obras, sus recopilaciones dispuestas y seleccionadas metódica o sistemáticamente y proceso de fabricación o producción, existirán en ellas tres derechos que habrá que regular: uno, los derechos del autor o autores de su contenido (es decir, los de las obras o datos que se han recopilado: artículos de revistas, estadísticas, sonidos, imágenes...); otro, los derechos del autor o autores de la selección o disposición de este contenido (es decir, los del autor o autores de la estructura de las bases de datos, que son propiamente los autores de las mismas); y el tercero, los derechos de los productores ofabricantes de las bases de datos, el llamado derecho «sui generis» o derecho especial, a causa de las inversiones sustanciales realizadas en ellas.

4.3 Respecto al primer derecho, el de autor o autores del contenido de las bases de datos, al no ser propiamente autores de una base de datos, las disposiciones citadas, que precisamente protegen a éstos, se limitan a establecer la obligación de respetarlo. Por lo que los autores de las obras recopiladas podrán libremente decidir si conceden o no la autorización de incluir sus obras en una base de datos; paticularmente podrán decidir si la autorización tiene carácter exclusivo o no.

Sin esta autorización tampoco podrán extraerse de ella.

Ahora bien, la bibliografía de obras protegidas, y, al parecer, los breves y elementales resúmenes (al no ser objeto de propiedad intelectual por no ser originales) no están protegidos por derecho de autor; luego no se necesitará la autorización del autor de ellos para incluirlos o extraerlos de una base de datos.

En cambio, ciertamente se necesitará cuando se trate de textos completos o de amplios resúmenes elaborados de una manera original.

4.4 Lo que sí regulan directa y exclusivamente estas disposiciones son los dos últimos derechos mencionados: los de los autores y los de los fabricantes de las bases de datos; siendo su finalidad la protección de ambos.

4.5 Ahora bien, el criterio para determinar o no la protección a los autores de una base de datos es exclusivamente la originalidad en el sentido de creación intelectual en la selección o disposición de los datos y obras recopiladas.

Es decir, esta selección y disposición han de constituir una creación intelectual propia o personal de su autor, no copiada o no simplemente repetida o plagiada. En general, una compilación con imaginación supondrá originalidad.

Este criterio, que es exclusivo, es una condición «sine qua non» para la protección.

Ello es consecuencia de considerar las bases de datos objeto también de propiedad intelectual, cuando haya originalidad en la selección de los datos y en la disposición de los materiales recopilados; porque esta condición es propia de todos los objetos de propiedad intelectual: libros, programas de ordenador, composiciones musicales...

Por lo tanto, el autor de una base de datos no original no está protegido jurídicamente por estas disposiciones; y sí lo está el autor de una original.

De esta manera, por faltar esta condición, la jurisprudencia de los Estados Unidos ha negado protección jurídica a bases de datos que recopilen listas exhaustivas de abonados al teléfono o de todas las profesiones de una región. También la ha negado a compilaciones de sentencias judiciales que aporten sólo mejoras insignificantes.

Por su parte, la jurisprudencia alemana la negó a bases de datos de bibliografías, de leyes editadas en CD-ROM o de guías telefónicas.

Por el contrario, la francesa encontró originalidad en una base de datos electrónica de convenios colectivos de trabajo, ya que su presentación temática denotaba una síntesis creativa del autor. 
Los casos podrían multiplicarse dando lugar a soluciones judiciales diversas, más o menos discutibles: «Tot capita, tot sententiae». En definitiva, serán los jueces los que decidirán la interpretación y consiguiente aplicación de las leyes.

4.6 Ni la Directiva 96/9 ni la Ley 5/1998 que estamos analizando regulan el derecho moral de los autores (exigencia del reconocimiento de su autoría y de la integridad de las recopilaciones, y decisión sobre su divulgación).

Consecuentemente, no se puede acudir a ellas para exigir o proteger este derecho. Por ello, hay que ir a la legislación de cada estado miembro (que en el caso de España es la Ley de Propiedad Intelectual) y al Convenio de Berna de 1973 sobre la protección de obras literarias y artísticas.

Lo que sí hacen tanto la Directiva como la Ley/1998 es simplemente reconocer que dicho derecho pertenece al autor de la base de datos.

Más técnicamente, la Ley 5/1998 no incorpora ninguna nueva redacción de esta materia a la Ley de Protección Intelectual.

4.7 En cambio, sí regulan los llamados derechos patrimoniales, o de explotación, de los autores de las bases de datos (reproducción, comunicación pública o acceso al público, distribución pública por venta y transformación de las bases de datos).

Estos derechos se consideran exclusivos del autor. Por lo tanto, sólo él puede ejercitarlos por sí o autorizar su ejercicio por otro.

Con intención de abarcar todos los casos posibles, ahora y en el futuro, en su articulado están redactados amplia y vagamente, sin concretar ni los medios ni la forma de realizarlos o de autorizarlos. Consiguientemente, cualquier medio o forma es válido; aunque expresamente no esté en el articulado.Y así:

4.7.1 La reproducción electrónica, o informática, no sólo la no electrónica, de las bases de datos, esto es, la conseguida por la carga o almacenamiento de bases de datos en la memoria o en el disco duro de un ordenador, hay que considerarla protegida por el derecho de reproducción.

4.7.2 Las transmisiones electrónicas «a la carta» de bases de datos; es decir, la transmisión por Internet a un ordenador personal u a otra unidad digital de usuario en un momento escogido por éste («a la carta», pues) están igualmente protegidas, al ser consideradas comunicación al público o de acceso al público, en cuanto que cualquier persona puede acceder a ellas desde el lugar y en el momento que ella misma elija.

Y ello sin perjuicio de los actos de reproducción que cumulativamente pueden llevar consigo estas transmisiones, que se cubrirán por el derecho específico de reproducción (por ejemplo, copias en papel por impresora de ordenador de una base de datos transmitida electrónicamente a éste o copias duraderas de ella en el disco duro).

4.7.3 La reordenación de una base de datos se considera también transformación de la misma, y por lo tanto protegida.

4.8 Por lo dicho, se protegen las bases de datos electrónicas y las no electrónicas, y tanto a sus autores como a sus fabricantes.

4.9 Limitaciones de los derechos patrimoniales. Los estados miembros de la U.E. podrán imponer las siguientes:

4.9.1 Reproducciones con fines privados de una base de datos. Es un caso de excepción o limitación en el que se protegen más las bases de datos electrónicas que las no electrónicas, al menos en las legislaciones francesa (ley de trasposición de la Directiva de 1 de julio de 1998) y española que siguen literalmente a la Directiva; ya que 
admiten la reproducción con fines privados sin autorización del autor, tratándose sólo de las bases de datos no electrónicas.

Ello significa que estas reproducciones de bases de datos electrónicas necesitarán de tal autorización.

Sin embargo, la ley alemana de trasposición de 22 de julio de 1997 dispone que no hace falta autorización para las elecrónicas. Luego, en la legislación alemana, tampoco se necesitará para las no electrónicas. En definitiva, ni para unas ni para otras.

No obstante, esta ley ha sido objeto de reparos por la U.E. Ahora bien, así como se admite una remuneración, en favor de los autores de obras de propiedad intelectual, por las fotocopias para usos privados, para compensarles por los perjuicios que se les ocasione, lo mismo cabría decir, por analogía o semejanza, de las reproducciones de las bases de datos con fines privados que se efectúen por Internet, ya que ésta pone a disposición de sus navegantes (una vez realizada la transmisión electrónica) obras protegidas (y las bases de datos son obras protegidas) dándoles la posibilidad de que las copien (en papel por la impresora del ordenador que recibe la transmisión o en el disco duro de éste).

En este sentido, la «Propuesta de Directiva 1999/C» 180/04 (publicada en el «Diario Oficial de las CC.EE» de 25 de junio de 1999) «relativa a la armonización de determinados aspectos de los derechos de autor y derechos afines en la Sociedad de la Información" regula que «se debe garantizar una compensación equitativa a todos los derechohabientes (autores, por ejemplo) por toda copia digital privada»

4.9.2 Utilización únicamente con fines ilustrativos de la ensenanza o de investigación científica, con tal de que se cite la fuente. $\mathrm{Y}$ «siempre que los derechohabientes reciban una compensación equitativa», añade la «Propuesta» dicha.

4.9.3 Utilización con fines de seguridad pública, o a efectos de un procedimiento administrativo o judicial.

En los dos casos, como en el primero, no hará falta autorización del autor de las bases de datos para las utilizaciones dichas. Y en estas dos limitaciones no se distinguen las bases electrónicas de las no electrónicas.

4.10 Otras limitaciones de los derechos patrimoniales. Los estados miembros de la U.E. podrán imponer además de las limitaciones mencionadas en la conclusión anterior las siguientes:

4.10.1 Los autores de las bases de datos no podrán oponerse ni a los préstamos ni a las reproducciones realizadas, sin finalidad lucrativa y con fines exclusivamente científicos, por instituciones públicas culturales o científicas (bibliotecas, hemerotecas, museos, archivos...). En el «Proyecto» antes citado se limitaba la excepción a las reproducciones efectuadas por bibliotecas o archivos con fines de archivo o conservación.

En el caso que tratamos, ¿se extiende a las reproducciones realizadas por los usuarios de estas instituciones y a las realizadas con el fin dicho de conservación?

En cualquier caso siempre que no haya finalidad comercial.

4.10.2 Tratándose de los préstamos de estas instituciones, los autores no tienen derecho a ninguna compensación, a diferencia de lo que sucede en las reproducciones con fines privados.

Estas limitaciones no están expresamente en la Ley $5 / 1998$, pues estaban ya en la Ley de Propiedad Intelectual, y se puede acudir a ésta, en cuanto que las bases de datos son también objeto de propiedad intelectual.

4.11 Usuario legítimo de una base de datos es la persona que tiene derecho a utilizarla, porque ha obtenido del titular (autor o fabricante) de la misma la autorización 
para ello o como consecuencia de compraventa del original o copia de la misma. En concreto, el usuario legítimo no necesitará autorización del autor para acceder al contenido de las bases de datos y a su normal utilización.

Si se trata de reproducción para fines privados no sólo el usuario legítimo tiene autorización para realizarla, sino cualquier persona.

La disposición referente al usuario legítimo es imperativa, por lo que hará nulo cualquier pacto en contrario que quiera imponer el autor.

4.12 La protección jurídica de las bases de datos alcanza por la Directiva nivel comunitario, no sólo nacional español; y alcanzará nivel internacional por el «Tratado de la OMPI», de 20 de diciembre de 1996, «sobre derecho de autor», cuando lo ratifiquen o se adhieran 30 países. Pero hasta ahora sólo lo han hecho 7, y entre ellos no está España que sí lo firmó, aunque no lo ha ratificado.

\section{Bibliografia}

NotA: Dadas las características especiales de este artículo, se incluye la bibliografía en orden cronológico.

(1989). Libro Verde sobre los derechos de autor y el reto de la Tecnología. Bruselas: Comisión de las CC.EE. (Comunicación). COM (88) 172 final, 237 p.

(1990). Acciones derivadas del Libro Verde. Bruselas: Comunicación de las CC.EE.COM (90) 584 final.

(1991). L'loriginalité de l'oeuvre en droit de auteur canadien. Marcel Dubé. En Cahiers Propieté Intelectuelle, v. 3, n. 3, p. 337-347.

(1992). Les banques de données géographiques au regard du droit de auteur. J. P. Trialle. Ibidem, v. 4, n. 2, p. 187-209.

(1994). El ABC del Derecho comunitario. K. D. Borchardt. Luxemburg: CC.EE.

(1995). Libro Verde sobre los derechos de autor ... en la Sociedad de la Información. Bruselas: Comisión de las CC.EE.COM (95) 382 final, 90 p.

(1996). Seguimiento de este Libro Verde. COM 96568 final, 30 p.

(1996). Jurisprudence: Bases de donnés, condition d’originalité. André Kéréver. En Rev. Intern. Droit Auteur (RIDA), n. 170, octubre, p. 242-9.

(1997). Las bases de datos en la Directiva comunitaria. Georges Konmantos. En RIDA, n. 171, janvier, p. 78-135.

(1997). Chronique des pays nordiques. En RIDA, n. 173, julio, p. 137-221; y n. 174, octubre, p. 124-173.

(1998-...). Lois et Traités de propieté intellectuelle. Ginebra: OMPI (publicación mensual).

(1998). La evolución del derecho de autor en Alemania desde 1973 hasta mediados de 1997. A. Dietz. En RIDA, n. 175, enero, p. 96-219; y n. 176, abril, p. 167-289.

(1998). Ley 5/1998, de 6 de marzo, sobre protección jurídica de las bases de datos... Fernando Bondía Román. En Actualidad Jurídica Aranzadi, año VIII, n. 371, 24 diciembre, p. 1-2 y p. 4-6.

(1998). Chronique de Jurisprudence. André Kéréver. En RIDA, n. 177, julio, p. 174-181.

(1998). Las columnas digitales del derecho de autor. Pierre-Yves Gautir. En Bol. Derecho Autor, v. XXXII, n. 3, julio-setiembre, p. 26-35.

(1999). Le droit de réproduction et l'Internet. Ysolde Geudreau. En RIDA, n. 178, oct., p. 3-81.

(1999). Chronique des Etats-Unis. Jane Ginsburg. En RIDA, n. 179, enero, p. 143-299; y n. 180, abril, p. 127-275.

(1999). Chronique de France: I. Législation. André Françon. En RIDA, n. 181, julio, p. 169-249.

(1999). Banche dati e multimedialtà. En Il Diritto di autore, año LXX, n. 1, enero-marzo, p. 1-11. 